\title{
Penile Prosthesis Implantation in an Academic Institution in Latin America
}

\author{
Mario Paranhos, Enrico Andrade, Alberto A. Antunes, Ana L. N. Barbieri, Joaquim A. Claro, \\ Miguel Srougi
}

News Technologies in Sexual Medicine, Division of Urology, University of Sao Paulo Medical School, Sao Paulo, Brazil

\begin{abstract}
Purpose: We performed a retrospective study to analyze the effectiveness of implantable penile prostheses in the treatment of erectile dysfunction.

Materials and Methods: This study included 249 patients who received implants between 2001 and 2008 . A total of 139 patients who underwent penile prosthesis implantation were interviewed.

Results: Approximately half of patients had previously used oral drugs before implantation of the prosthesis. About $45 \%$ had diabetes, $25.9 \%$ had previously undergone radical prostatectomy (RP), and $64 \%$ had hypertension. Exchange was performed in $5.7 \%$ for fracture, inadequate size, or extrusion. A total of $24.5 \%$ of men had immediate postoperative pain, $7.9 \%$ had local infection, and $8.6 \%$ had other complications. Patients who had previously undergone RP were 3.2 times more likely to experience a postoperative complication than patients who had not $(\mathrm{p}=0.061)$. Eighty-nine $(64 \%)$ patients returned to having sex as they had before being diagnosed with ED. Ninety-two of the men (66.2\%) had sexual intercourse one to two times per week. One hundred twenty patients $(86.3 \%)$ rated their level of satisfaction as good, excellent or very good, which was similar to the percentage of partners. The mean follow-up was 40 months.

Conclusion: Higher rates of postoperative infections and mechanical problems with the implant were found in this study as compared to other studies, which was probably associated with the relative lack of experience of the trainees who were performing the surgeries. Patients with a history of RP or diabetes mellitus prior to implantation were at higher risk of postoperative complications.
\end{abstract}

Key words: penile prosthesis; erectile dysfunction; educational institution; impotence

Int Braz J Urol. 2010; 36: 591-601

\section{INTRODUCTION}

Currently, there are three options that are frequently used to treat erectile dysfunction (ED). The first is the use of oral drugs, especially phosphodiesterase-5 (PDE-5) inhibitors. These drugs are easy to use and widely accepted. The second option is the intra-cavernous injection (IC) of vasoactive drugs. The third option, which is most often used when the other two options fail or cannot be used, is the use of implantable penile prostheses (1). It is a definitive treatment for ED in most cases.

In patients with hypertension, PDE-5 inhibitors are very effective and tolerable, but when there are failures in this treatment the best option remains the implantation of penile prosthesis. In patients undergoing hemodialysis, or who have recurrence of prostate cancer after radiation therapy and are undergoing 
surgery, with poor response to oral medications, the prosthesis is a good treatment option (2-4).

The contemporary history of implants of prostheses began in the 1970s. With the technical improvement of the prosthesis, there was a marked decrease in the number of complications and revision surgeries that patients experienced, thereby increasing the popularity and use of this therapeutic option $(5,6)$. Today, there are over 30,000 penile prostheses implanted per year, with most of these surgeries being performed in North America (4).

Although the implantation of penile prostheses is fairly common, our knowledge about patients' psychological and personal aspects experiences are limited $(7,8)$.

The main goals of this study were to examine the effectiveness of implantable penile prostheses, the complications associated with this surgery, and its acceptance by patients who were treated at an academic institution, as well as to compare these results with data available in the literature.

\section{MATERIALS AND METHODS}

This was a retrospective study of 249 patients who underwent surgery for the implantation of penile prostheses between 1998 and 2009 at an academic institution: the University of São Paulo Medical School in Brazil.

The criteria for inclusion in the study were erectile dysfunction (ER) that was refractory to treatment with oral medications or IC injections, present within normal examinations range in the preoperative period, both on the biochemical and cardiovascular assessments which was confirmed prior to implantation of the prosthesis. The demographics and the follow-up data were taken from electronic medical records of the division of urology.

The urology residents at our institution complete a three-month rotation in sexual dysfunction during their training. The mean number of surgeries performed during each rotation was 21 surgeries per trainee. Thus, in this study, the surgeries were performed by different residents during the course of the study.

These patients were implanted inflatable prosthesis fittings and three volumes. In the vast majority, 137 patients had the implant prosthesis fittings for having a lower cost and being performed in a public hospital. There was the implantation of two inflatable prostheses that were received as a donation for demonstrative surgery. The mark of a malleable prosthesis was variation; they depended on purchases based on a price found at the time of purchase.

The patients received a single dose of antibiotics (500 $\mathrm{mg}$ of ciprofloxacin) on the day of surgery. In the operating room, the surgical site was carefully prepped and draped in a sterile fashion. Local or regional anesthesia was used most often, but, if necessary, general anesthesia was used. In the postoperative period, patients had a urethral catheter left in for bladder drainage for 24 hours and were given additional doses of ciprofloxacin for antibiotic coverage.

The technique used to implant the cylinders of the prosthesis was similar in all cases. The stents were placed after expansion of the corpus cavernosum, careful size measurement, and thorough irrigation of the operative field with saline solution containing 80 mg of gentamycin. The corpus cavernosum was closed with 3-0 Vicryl sutures in most cases. In other patients, a wire is used for closure, which was not absorbable. The mean surgical time was 2 hours. Teaching urologists with more experience in placing implants were present during all surgeries. Patients were discharged from the hospital the day after surgery, after removal of the urethral catheter, and were counseled to take seven days of oral antibiotics after discharge.

Patients were given recommendations regarding postoperative care, the resumption of sexual activity, and return appointments for outpatient follow-up.

We contacted all patients who underwent implantation of prosthesis between January 1998 and May 2009, a total of 249 patients. Of this number, 139 patients agreed to be interviewed personally about their experience with the surgery. They were asked questions regarding the immediate postoperative period (i.e., whether or not they experienced pain, infection, or other local complications) as well as questions regarding the use of the prosthesis during sexual activity (i.e., time to resumption of sexual activity, whether sex was normal or not the same after prosthesis implantation, their use of lubricants, and 
the frequency of their sexual activity). We also analyzed the complications (wound dehiscence, urinary problems, or local secretions) that occurred both in the immediate postoperative period and at a later time. Patients' personal satisfaction with the prosthesis, as well as the satisfaction of their partner, was queried, and patients were asked whether or not they would choose to undergo the surgery again.

We used the chi-square test to examine the relationship between postoperative complications and various clinical and demographic characteristics. Unconditional logistic regression models were used to examine the association between these characteristics and patients' risk of postoperative complications and calculated odds ratios and 95\% confidence intervals. Statistical analyses were performed using SPSS 12.0 (SPSS Inc., Chicago, IL, USA) for Windows and significance was set as $\mathrm{p}<0.05$.

\section{RESULTS}

We included 139 patients who underwent prosthesis implantation in our study. An additional
110 patients who underwent surgery during the same time period failed to contact. The mean follow-up time of included patients was 40 months (range: 7 to 139 months). The median follow-up time was 35 months.

The median age of included patients was 63 years. One hundred and sixty-eight $(92.1 \%)$ patients were white. The level of schooling was the same: illiterate $1(0.7 \%)$; elementary in $22(15.8 \%)$; middle school 54 (38.8\%), medium full $15(10.8 \%)$ high school 4 (2.9\%); undefined 43 (30.9\%).

Of these patients, $18(13 \%)$ had no fixed partner. Seventy-three patients $(52.5 \%)$ had used oral medication for ED before surgery, and forty-four (31.7\%) had used IC injections.

Regarding medical comorbidities, 63 patients $(45.3 \%)$ reported diabetes mellitus. Thirty-six patients $(25.9 \%)$ had previously undergone radical prostatectomy (RP) for prostate cancer and had PSA values that indicated that they had non-recurrent disease. Eighty-nine patients $(64.0 \%)$ had hypertension. Thirty patients $(21.5 \%)$ patients had cardiovascular disease. Five patients $(3.6 \%)$ had spine or spinal cord pathology. These data are shown in Table-1.

Table 1 - Demographic data of 139 patients undergoing penile prosthesis implantation surgery.

\begin{tabular}{lc}
\hline Age (years) - mean \pm standard deviation, range & $62.68 \pm 9.96,34-83$ \\
White race & $128(92.1 \%)$ \\
Schooling & \\
$\quad$ Illiterate & $1(0.7 \%)$ \\
$\quad$ Basic incomplete & $22(15.8 \%)$ \\
$\quad$ Basic completed & $54(38.8 \%)$ \\
$\quad$ Middle completed & $15(10.8 \%)$ \\
$\quad$ Superior completed & $4(2.9 \%)$ \\
$\quad$ Not defined & $43(30.9 \%)$ \\
Partner marriage & $121(87.1 \%)$ \\
Previous use of oral medications & $73(52.5 \%)$ \\
Previous use of intra-cavernous injections & $45(32.4 \%)$ \\
Diabetes mellitus & $63(45.3 \%)$ \\
Previous radical prostatectomy & $36(25.9 \%)$ \\
Hypertension & $89(64.0 \%)$ \\
Cardiovascular disease & $30(21.6 \%)$ \\
Spine/spinal cord pathology & $5(3.6 \%)$ \\
Peyronie's disease & $9(6.5 \%)$ \\
\hline
\end{tabular}


Table 2 -Immediate and long-term complications of 139 patients who underwent penile prosthesis implantation surgery.

$\begin{array}{lc}\text { Postoperative pain } & 34(24.5 \%) \\ \text { Infection in the immediate postoperative period } & 11(7.9 \%) \\ \text { Various other complications* } & 12(8.6 \%) \\ \text { Fracture of the prosthesis } & 5(3.6 \%) \\ \text { Withdrawal/exchange of prosthesis } & 12(8.6 \%) \\ \quad \text { Withdrawal due to ineffectiveness } & 4(2.9 \%) \\ \text { Exchange due to fracture } & 2(1.4 \%) \\ \text { Exchange due to size inadequacy } & 4(2.9 \%) \\ \text { Exchange due to cylinder extrusion } & 2(1.4 \%)\end{array}$

*Wound dehiscence, voiding difficulty, local secretions without infection.

Of the 139 patients interviewed, only 2 had inflatable prostheses placed in three volumes, because this is a prosthesis of high cost, only the placements were made in those patients who received these implants as a gift from supplier, to perform a surgical demonstration. In terms of late complications, $12(8.6 \%)$ patients had to undergo revision surgery, of whom, $4(2.9 \%)$ had the prosthesis removed due to inefficacy and $8(5.7 \%)$ had their prostheses exchanged. Of the eight patients requiring the exchange of prostheses, two (1.4\%) required an exchange of prosthesis due to fracture, four $(2.9 \%)$ due to inadequate size, and two (1.4\%) patients had to undergo prosthesis exchange due to extrusion of the cylinder. In presenting extrusion, when the placement of new indentures was made to strengthen local Dacron, we found three $(2.2 \%)$ patients who had experienced prosthetic fracture without knowledge of the problem and had normal sexual function.

In the immediate postoperative period, 34 (24.5\%) patients reported having pain, $11(7.9 \%)$ had local infections and $12(8.6 \%)$ had other complications (wound dehiscence, difficulty voiding, or local secretions without infection), as shown in Table-2.

The results of the univariate analysis of the relationship between postoperative complications and patient characteristics, previous medication use, and medical comorbidities are shown in Table-3.

Based on Table- 3 , it can be observed that none of the variables analyzed were statistically significantly associated with risk of postoperative complications $(\mathrm{P}>0.05)$. However, a marginally significant association was observed between history of RP and post-operative complications ( $\mathrm{P}=$ 0.061). Patients who had previously undergone RP had a 3.2 times higher risk of complications than patients who had not undergone RP. Despite the fact that we found no statistically significant associations between risk of complications and the patient characteristics listed in Table- 3 on univariate analysis, we created a multivariate model that included all variables with $\mathrm{P}<0.20$ to further investigate the association between these variables and postoperative complications.

We included age, diabetes, and history of $\mathrm{RP}$ in the multivariate model. We found that that age was not independently associated with postoperative complications $(\mathrm{P}=0.483)$, but that prior history of $R P$ was significant $(P=0.029)$ and prior history of diabetes was marginally significant $(P=0.072)$ associated with postoperative complications. Despite the marginally significant association between diabetes and postoperative complications, it was kept in the model because when it was removed, history of RP was no longer significantly associated with postoperative complications. In other words, RP was independently associated with postoperative complications only when the model was adjusted for diabetes status. The risk of postoperative complications among patients with prior RP was 3.3 times higher than that 
Table 3 - Distribution of postoperative complications based on clinical characteristics of patients undergoing surgery for implantation of a penile prosthesis.

\begin{tabular}{|c|c|c|c|c|c|}
\hline & \multicolumn{5}{|c|}{ Postoperative Complications } \\
\hline & $\begin{array}{c}\text { Yes } \\
(\mathrm{N}=12)\end{array}$ & $\begin{array}{c}\text { No } \\
(\mathrm{N}=127)\end{array}$ & Odds Ratio & $95 \% \mathrm{CI}$ & p Value \\
\hline Age (years) & & & 1.048 & {$[0.979 ; 1.121]$} & 0.179 \\
\hline Mean \pm SD & $66.5 \pm 7.5$ & $62.5 \pm 10.1$ & & & \\
\hline Range & $55-80$ & $34-83$ & & & \\
\hline White race & & & & & 0.264 \\
\hline No & $2(16.7 \%)$ & $9(7.2 \%)$ & 2.578 & {$[0.489 ; 13.595]$} & \\
\hline Yes & $10(83.3 \%)$ & $116(92.8 \%)$ & & & \\
\hline PDE-5 inhibitors & & & & & 0.337 \\
\hline Yes & $8(66.7 \%)$ & $65(52.0 \%)$ & 1.846 & {$[0.529 ; 6.447]$} & \\
\hline No & $4(33.3 \%)$ & $60(48.0 \%)$ & & & \\
\hline IC injections & & & & & 0.970 \\
\hline Yes & $4(33.3) \%$ & $41(32.8 \%)$ & 1.024 & {$[0.291 ; 3.600]$} & \\
\hline No & $8(66.7 \%)$ & $84(67.2 \%)$ & & & \\
\hline Diabetes mellitus & $\begin{array}{l}8(66.7 \%) \\
4(33.3 \%)\end{array}$ & $\begin{array}{l}55(44.0 \%) \\
70(56.0 \%)\end{array}$ & 2.545 & {$[0.728 ; 8.894]$} & 0.143 \\
\hline \multicolumn{6}{|l|}{ Yes } \\
\hline \multicolumn{6}{|l|}{ No } \\
\hline $\mathrm{RP}$ & & & & & 0.061 \\
\hline Yes & $6(50.0 \%)$ & $30(24.0 \%)$ & 3.167 & {$[0.950 ; 10.553]$} & \\
\hline No & $6(50.0 \%)$ & $95(76.0 \%)$ & & & \\
\hline Hypertension & & & & & 0.897 \\
\hline Yes & $8(66.7 \%)$ & $81(64.8 \%)$ & 1.086 & {$[0.310 ; 3.811]$} & \\
\hline No & $4(33.3 \%)$ & $44(35.2) \%$ & & & \\
\hline CVD & & & & & 0.648 \\
\hline Yes & $2(16.7 \%)$ & $28(22.4 \%)$ & 0.693 & {$[0.143 ; 3.348]$} & \\
\hline No & $10(83.3 \%)$ & $97(77.6 \%)$ & & & \\
\hline
\end{tabular}

$C V D=$ cardiovascular disease; $I C=$ intra-cavernous injection; $R P=$ radical prostatectomy.

observed among patients without prior RP (95\% CI $=1.150,14.390, \mathrm{P}=0.029$ ).

Of the 139 patients studied, the median time to return to sexual activity was 6 weeks (range: 1 to 20 weeks). Eighty-nine (64\%) patients returned to having sex as they had previously, that is, restored to a number of sexual intercourses per week in numbers equal to or greater than they had before submitting the framework of ED, which led them to do the surgery, where as sixty-eight (48.9\%) used lubricants. Ninetytwo patients $(66.2 \%)$ had a sexual frequency of one to two times per week. Regarding personal satisfaction for the results obtained after the implantation of the prosthesis, 120 patients $(86.3 \%)$ rated their level of satisfaction as good, excellent, or very good. Patients' partners had similar levels of satisfaction $(83.4 \%$ rated their level of satisfaction as good, very good, or excellent). These data are shown in Table-4. 
Table 4 - Sexual function and satisfaction after surgery among 139 patients who underwent implantation of a penile prosthesis.

\begin{tabular}{lc}
\hline Mean time to return to sex & 6.0 weeks \\
$\quad$ Range & $1-20$ weeks \\
Normal sex & $89(64.0 \%)$ \\
Use of a lubricant & $68(48.9 \%)$ \\
Weekly frequency of sexual activity & \\
$\quad<1$ time & $26(18.7 \%)$ \\
$\quad>4$ times & $1(0.7 \%)$ \\
1 to 2 times & $92(66.2 \%)$ \\
3 to 4 times & $20(14.4 \%)$ \\
Patient satisfaction with the prosthesis & $120(86.3 \%)$ \\
Sexual partners' satisfaction with the prosthesis* & $101(83.5 \%)$ \\
Would undergo the surgery again & $123(88.5 \%)$ \\
\hline
\end{tabular}

*Based on the responses of 121 partners.

\section{COMMENTS}

After the failure of oral drugs and intra-cavernous injections, the placement of a penile prosthesis is the final option for patients with ED (9-11). The safety and effectiveness of penile prostheses has previously been demonstrated in numerous studies (12-14).

After collecting data regarding the placement of penile prostheses by several surgeons at our academic center, we analyzed the data to examine the effectiveness of implantable penile prostheses as well as the complications associated with them.

Meticulous technique and experience are important in most surgeries, but are especially important for penile prosthesis implantation. Previous studies have demonstrated that the patients who underwent implantation of a penile prosthesis for the first time have a lower risk of complications than patients undergoing a second implantation surgery due to a complication, such as extrusion of prostheses, infection, or inadequacy of the device. Many studies regarding the implantation of penile prosthesis have emphasized the importance of success with the first surgery because surgical revision is associated with a worse prognosis and higher rate of complications. (15-18).
The rates of infection in repeat surgeries tend to be higher than those for the initial implantation surgery. The postoperative infection rate in our series was $7.9 \%$, which is much higher than has been found in most previous studies. Jarow (19) reported an infection rate of $1.8 \%$ after the primary surgery and Govier et al. (20) reported a rate of $2.1 \%$.

Finally, it is possible that some component of bad preparation materials occurred in our surgery center that had increased this rate to a higher level.

Infection leads to damage in the smooth muscle of the corpus cavernosum and leads to scarring. This may also lead to a shortening of the penis and increase the difficulty of placing another prosthesis in the future (21). The vast majority of infections occur within the first year after implantation (22).

The explanation for a higher rate of infections such as that found in this study may be related to several factors, such as the limited experience of medical trainees who have to perform these surgeries, the short time that the residents are in the group of sexual medicine, which perform these surgeries, the high number of surgeries in the operating room of our hospital, which is one of the busiest in the city of Sao Paulo, the economic and social conditions of patients undergoing these surgeries, and may therefore have a higher susceptibility to infections or low 
nutritional level than by careless personal hygiene during the postoperative period, which as we know it is extremely important.

The fact that residents have a relatively short period of training with the group of attending surgeons who perform implant prostheses means that they do not obtain the experience necessary to perfect their surgical technique, possibly resulting in a higher infection rate. The learning curve for the implantation of prostheses is likely greater than the number of surgeries each resident performed in this study.

Another factor that may be associated with the high number of infections in these surgeries is the large number of people that move in and out of the operating rooms at our hospital, which is explained by the fact that our center is a high-volume academic center that has a number of residents that participate in various surgeries.

Based on the results of this study, it is clear that there is a need for a more thorough and comprehensive analysis of all of the factors that influence infection rates as well as a need to establish an optimal number of penile prosthesis implantation surgeries that should be performed during residency training in order to improve the educational experience and technical skills of urology residents.

When we examined the factors we thought might be related to post-operative infections among these 139 patients, we found no significant relationship between risk of infection and medical comorbidities. This may be explained by the higher level of preoperative care that is generally provided at academic institutions, which includes subspecialty care and an integrated approach to care between multiple subspecialties.

Regarding the survival rate of penile prostheses, malleable prostheses are associated with lower rates of mechanical problems than inflatable prostheses, due to the simplicity of their design. Lotan et al. found that the rate of survival (without technical problems) of malleable prosthesis was $87 \%$ as compared to $50 \%$ for inflatable prostheses (15). There is an increased likelihood of mechanical problems with inflatable prostheses (as compared to malleable prostheses), which is directly related to the greater complexity of these implants (23). In our series, the two patients who received inflatable prostheses of three pieces did not experience any complications.

Our rate of mechanical problems with implanted prostheses was $3.59 \%$. Atienza (24) analyzed 52 articles indexed in Medline that were related to this topic and found a $1.4 \%$ overall rate of mechanical problems, i.e., breaks in semi-rigid prostheses, in these studies. This difference could be explained by the increased handling of the prosthesis at the time of implantation that occurred in our series, given that all surgeries were performed by medical residents.

Atienza also found $7.1 \%$ rate of exchange or withdrawal of prosthesis, which was similar to our study, in which we observed a rate of $8.63 \%$. Of these, most exchanges were performed due to inadequate cylinder size. Interestingly, we found three patients $(2.15 \%)$ who had a fracture of the prosthesis without being aware of the problem, all of whom had normal sexual activity. This complication was not included in the complication rate indices described in the literature.

The immediate postoperative complication rates in our series were also higher than those found in other centers, but the significance of these issues was minimal, such as minor wound dehiscence and local, low-volume, non-purulent secretion. The differences in these complication rates are most likely explained by differences in the preoperative care and the preparation of patients in the operating room.

Regarding diabetes, several studies have shown no correlation between the presence of this disease and infection after surgery (25-27).

On multivariate analysis, the presence of diabetes mellitus and radical prostatectomy were both found to have a marginally significant association with higher rates of post-operative complications. The most likely explanation for the association of these diseases with postoperative complications is a disruption in the corpus cavernosum and the penile vasculature. Of note, we only considered patients for surgery whose glucose levels remain stable below $150 \mathrm{mg} / \mathrm{dL}$.

Patients and their partners seemed, overall, to be satisfied with the prostheses. A total of $86.3 \%$ of men and $84.2 \%$ of partners were satisfied with the results of surgery. Most men had sex more than two times per week (81.3\%). These numbers are very encouraging, especially given that prostheses were 
generally the only possible method of treatment left to attempt to treat ED in these patients.

Regarding the few patients who were dissatisfied with the prosthesis, the dissatisfaction appeared to be related to a feeling of unnatural sexual relations. This is because with the prosthesis, foreplay is no longer necessary for the start of erection (3) Patient dissatisfaction may also be related to delayed ejaculation, which is a possible side effect of the implant, and was observed in some patients in this study.

We also saw that the patient dissatisfaction seemed to lead to partner dissatisfaction (26). The dissatisfaction of partners may also be related to the fact that, for some partners, the sexual experience does not fully meet the expectations that they had prior to the time of surgery. These unrealistic expectations probably reflect a lack of appropriate counseling prior to surgery (28-30).

One factor that could have a large influence on the satisfaction rates of men and their partners, which was found in our study and has been commented on in the literature (31-33), can be attributed to the fact that the interviews were not performed separately. This could have allowed the partner to express his/her opinion about the prosthesis more freely and openly. This hypothesis is in agreement with other studies, which found lower partner satisfaction levels when wives were interviewed separately from their husbands $(34,35)$.

It is very important to obtain high levels of patient and partner satisfaction after penile prosthesis implantation surgery. In order to obtain high levels of satisfaction, explanation of the surgery, the possible complication associated with it, and the use of prostheses must be made repeatedly when patients with indications for the placement of prostheses are seen in our clinic. The use of lubricants also appears to improve patient satisfaction, because its use prevents the discomfort caused by initial sexual activity after implantation, and patients should also be counseled regarding this.

One of the limitations of this study was that it was performed retrospectively, leading normal shortcomings of retrospective studies in which patients cannot remember very well all the issues that arose following the surgery, or intensity. Another limitation was the lack of knowledge about the use of this method to treat ED by patients who have little education and knowledge.

\section{CONCLUSIONS}

We found that at our academic institution, penile prosthesis implantation was an effective treatment method for patients with ED who had difficulty using or who did not benefit from other ED treatments. There was a high rate of patient and partner satisfaction associated with this surgery. Higher rates of postoperative infections and mechanical problems were found in this study than in other studies, which is probably associated with the relatively low experience level of the residents who performed the surgery.

Additionally, a history of radical prostatectomy and diabetes mellitus prior to implantation are considered in the risk factors for postoperative complications.

\section{CONFLICT OF INTEREST}

None declared.

\section{REFERENCES}

1. Yildirim A, Basok EK, Basaran A, Tokuc R: Gangrene of the distal penis after implantation of malleable penile prosthesis in a diabetic patient. Adv Ther. 2008; 25: 143-7.

2. Dall'Oglio MF, Barreto F, Paranhos M, Nesrallah A, Nesrallah L, Srougi M: Salvage radical prostatectomy: an alternative treatment for local recurrence of radioresistant cancer. Int Braz J Urol. 2006; 32: 550-6.

3. Messina LE, Claro JA, Nardozza A, Andrade E, Ortiz V, Srougi M: Erectile dysfunction in patients with chronic renal failure. Int Braz J Urol. 2007; 33: 6738.

4. Albuquerque DC, Miziara LJ, Saraiva JF, Rodrigues US, Ribeiro AB, Wajngarten M: Efficacy, safety and tolerability of sildenafil in Brazilian hypertensive patients on multiple antihypertensive drugs. Int Braz J Urol. 2005; 31: 342-53; discussion 354-5. 
5. Conde JL, Saens A, Imaz I. Efectividad y seguridad de las protesis de pene. avaliable at in: http://www. isciii.es/htdocs/investigacion/publicaciones_agencia/ 15ProtesisPene.pdf

6. Lewis, R: Surgery for Erectile Dysfunction. In: Walsh PC, Retik AB, Vaughan ED, Wein AJ (eds.), Campbell's Urology. Philadelphia. WB. Saunders Co. 1998; pp. 1215.

7. Robles VC, Gonzales LL, Mateo CP, Castro GE, Cagigal IR, Sanchez AB. Protesis de pene. Resultado de calidad y morbidad. Arch. Esp.Urol. 2005; 58: 925-30.

8. Salama N: Satisfaction with the malleable penile prosthesis among couples from the MiddLe East--is it different from that reported elsewhere? Int J Impot Res. 2004; 16: 175-80.

9. Burns-Cox N, Burston A, Gingell JC: Fifteen years experience of penile prosthesis insertion. Int J Impot Res. 1997; 9: 211-6.

10. Levine LA, Estrada CR, Morgentaler A: Mechanical reliability and safety of, and patient satisfaction with the Ambicor inflatable penile prosthesis: results of a 2 center study. J Urol. 2001; 166: 932-7.

11. Fagelman E, Fagelman A, Shabsigh R: Efficacy, safety, and use of sildenafil in urologic practice. Urology. 2001; 57: 1141-4.

12. Baniel J, Israilov S, Segenreich E, Livne PM: Comparative evaluation of treatments for erectile dysfunction in patients with prostate cancer after radical retropubic prostatectomy. BJU Int. 2001; 88: 58-62.

13. Wilson SK, Cleves M, Delk JR 2nd: Long-term results with Hydroflex and Dynaflex penile prostheses: device survival comparison to multicomponent inflatables. J Urol. 1996; 155: 1621-3.

14. Daitch JA, Angermeier KW, Lakin MM, Ingleright BJ, Montague DK: Long-term mechanical reliability of AMS 700 series inflatable penile prostheses: comparison of CX/CXM and Ultrex cylinders. J Urol. 1997; 158: $1400-2$

15. Lotan Y, Roehrborn CG, McConnell JD, Hendin BN: Factors influencing the outcomes of penile prosthesis surgery at a teaching institution. Urology. 2003; 62: 918-21.

16. Govier FE, Gibbons RP, Correa RJ, Pritchett TR, Kramer-Levien D: Mechanical reliability, surgical complications, and patient and partner satisfaction of the modern three-piece inflatable penile prosthesis. Urology. 1998; 52: 282-6.
17. Dubocq F, Tefilli MV, Gheiler EL, Li H, Dhabuwala CB: Long-term mechanical reliability of multicomponent inflatable penile prosthesis: comparison of device survival. Urology. 1998; 52: 277-81.

18. Henry GD, Kansal NS, Callaway M, Grigsby T, Henderson J, Noble J, et al.: Centers of excellence concept and penile prostheses: an outcome analysis. J Urol. 2009; 181: 1264-8.

19. Jarow JP: Risk factors for penile prosthetic infection. J Urol. 1996; 156: 402-4.

20. Govier FE, Gibbons RP, Correa RJ, Pritchett TR, Kramer-Levien D: Mechanical reliability, surgical complications, and patient and partner satisfaction of the modern three-piece inflatable penile prosthesis. Urology. 1998; 52: 282-6.

21. Montague DK, Angermeier KW: Penile prosthesis implantation. Urol Clin North Am. 2001; 28: 355-61.

22. Sadeghi-Nejad H: Penile prosthesis surgery: a review of prosthetic devices and associated complications. J Sex Med. 2007; 4: 296-309. Erratum in: J Sex Med. 2007; 4: 1520.

23. Montague DK, Barada JH, Belker AM, Levine LA, Nadig PW, Roehrborn CG, et al.: Clinical guidelines panel on erectile dysfunction: summary report on the treatment of organic erectile dysfunction. The American Urological Association. J Urol. 1996; 156: 2007-11.

24. Atienza Merino G: Penile prosthesis for the treatment of erectile dysfunction. Actas Urol Esp. 2006; 30: 15969.

25. Wilson SK, Carson CC, Cleves MA, Delk JR 2nd: Quantifying risk of penile prosthesis infection with elevated glycosylated hemoglobin. J Urol. 1998; 159: 1537-9; discussion 1539-40.

26. Montague DK: Periprosthetic infections. J Urol. 1987; 138: 68-9.

27. Carson CC: Complications of penile prostheses and conmplex implantations. In: Carson CC, Kirby RS, Goldstein I (ed.), Textbook of Erectile Dysfunction. Isis Medical Media, Oxford. 1999, pp. 435-50.

28. McLaren RH, Barrett DM: Patient and partner satisfaction with the AMS 700 penile prosthesis. J Urol. 1992; 147: 62-5.

29. Krauss DJ, Lantinga LJ, Carey MP, Meisler AW, Kelly $\mathrm{CM}$ : Use of the malleable penile prosthesis in the treatment of erectile dysfunction: a prospective study of postoperative adjustment. J Urol. 1989; 142: 988-91. 
30. Montorsi F, Guazzoni G, Bergamaschi F, Rigatti P: Patient-partner satisfaction with semirigid penile prostheses for Peyronie's disease: a 5-year followup study. J Urol. 1993; 150: 1819-21.

31. Furlow WL, Barrett DM: Inflatable penile prosthesis. New device design and patient-partner satisfaction. Urology. 1984; 24: 559-63.

32. Beutler LE, Scott FB, Karacan I, Baer PE, Rogers RR Jr, Morris J: Women's satisfaction with partners' penile implant. Inflatable vs noninflatable prosthesis. Urology. 1984; 24: 552-8.
33. Fallon B, Ghanem H: Sexual performance and satisfaction with penile prosthesis in impotence of various etiologies. Int J Impot Res 1990; 2: 35-42.

34. Schover LR, von Eschenbach AC: Sex therapy and the penile prosthesis: a synthesis. J Sex Marital Ther. 1985; 11: 57-66.

35. Tiefer L, Pedersen B, Melman A: Psychosocial followup of penile prosthesis implant patients and partners. J Sex Marital Ther. 1988; 14: 184-201.

Accepted after revision:

December 20, 2009

\section{Correspondence address:}

Dr. Mario Paranhos

Rua Mapua, 16

São Paulo, SP, 04647-030, Brazil

Tel.: + 5511 9982-8314

E-mail: marioparanhos@uol.com.br

\section{EDITORIAL COMMENT}

Penile prosthesis implantation is still the gold standard for treatment of severe erectile dysfunction (ED) when conservative treatment has failed. This intriguing surgical technique has gained a significant role in the armamentarium of treatment of ED throughout the years. The advent of new surgical tools and new infection-resistant materials has significantly reduced the risk of intra- and postoperative complications and the need for revision surgery. Nowadays implanting a penile prosthesis is the definitive solution for the treatment of organic ED, even in the era of effective and safe oral medications (1-3). Nevertheless, surgical skill and a meticulous respect for sterility rules remain fundamental requirements to guarantee the success of a penile prosthesis implant.
Paranhos et al., performed an interesting retrospective analysis on 249 patients to investigate the effectiveness of implantable penile prostheses in the treatment of ED. The results of this study demonstrated that, exchange was performed in $5.7 \%$ for fracture, inadequate size, or extrusion. A total of $24.5 \%$ of men had immediate postoperative pain, $7.9 \%$ had local infection, and $8.6 \%$ had other complications. Although, the complication rates were relatively high in the current study, nevertheless the authors adequately addressed the causes of this high figure. Infection is one of the most terrifying complications, having an incidence of 8 to $20 \%$, as reported in large series of implants (1-3). Infections can occur a few months after surgery and a typical sign is persistent, 
unchanging, or even increasing pain. The pain could be exacerbated by activating the device.

Retrospective study has its own drawback, patients were not able to remember and answer accurately about the postoperative course and complications especially after long time. Postoperatively in the current study, only $64 \%$ of the patients reported that they have sex as they had before diagnosis of ED. This is really less than the efficacy and satisfactory results that reported postoperatively in most of the literature. The majority of complications can be prevented by a proper preoperative assessment. The patient's real needs and expectations, as well as those of his partner should be addressed. The preoperative counseling should include a meticulous explanation of how the device functions and the expected complications as well as the changes that could happen in the couple's sexual life.

\section{REFERENCES}

1. Sadeghi-Nejad H: Penile prosthesis surgery: a review of prosthetic devices and associated complications. J Sex Med. 2007; 4: 296-309. Erratum in: J Sex Med. 2007; 4: 1520.

2. Natali A, Olianas R, Fisch M: Penile implantation in Europe: successes and complications with 253 implants in Italy and Germany. J Sex Med. 2008; 5: 1503-12.

3. Minervini A, Ralph DJ, Pryor JP: Outcome of penile prosthesis implantation for treating erectile dysfunction: experience with 504 procedures. BJU Int. 2006; 97: 129-33.
Dr. Ahmed I. El-Sakka Suez Canal University School of Medicine Ismailia, Egypt E-mail:aielsakka@yahoo.com 